\title{
Challenges in Communication Skills Education in Medicine: Based on Personal Experience and Reflection
}

Young-Mee Lee

Department of Medical Education, Korea University College of Medicine, Seoul, Korea

\section{의료 커뮤니케이션 교육에서 도전과제: 개인적 경험과 성찰을 토대로}

고려대학교 의과대학 의학교육학교실

이영미

환자와 효과적으로 커뮤니케이션 하는 것은 의사가 갖추어 야 할 기본적 임상 자질에 하나임은 주지의 사실이며 체계적 인 교육을 통하여 커뮤니케이션 기술과 대인관계 형성 능력 은 학습되고 유지될 수 있다는 것 역시 잘 알려져 있는 사실이 다[1]. 이제 국내에서도 커뮤니케이션 교육과정은 의과대학 에서 당연히 가르쳐야 하는 교과목으로 자리를 잡아가고 있 다. 그러나 국내 의료 커뮤니케이션 교육은 도입 초기단계로 교육자료, 교수방법, 평가 및 대학의 재정적 지원 등 여러 방 면에서 지속적인 연구와 발전이 필요한 분야이다.

커뮤니케이션을 효과적으로 가르치고 배우는 방법에 대해 서는 기존의 선행연구와 지침서를 참고하면 쉽게 구할 수 있 고, 교육과정을 개발하고 편성하는 것 역시 어려운 일은 아니 다. 그러나 교육과정의 운영의 실제와 소기의 교육목표와 성 과에 도달하는 것은 결코 쉬운 일이 아니다. 이 글에서는 커뮤 니케이션 교육방법에 대한 이론이나 다양한 교수방법을 나열 하기보다는 교육과정을 운영하면서 필요한 실제적인 이야기 들을 하고자 한다. 즉, 지난 6년 동안 필자의 경험을 토대로 커뮤니케이션 교육을 성공적으로 이끌어갈 수 있는 전략과 도전적 과제에 대하여 간략히 제시하고자 한다.

\section{1. 커뮤니케이션 기술 교육은 행동의 변화를 유도해 야 하는 것이므로 ‘경험학습’이 중요하다}

이 말은 커뮤니케이션에 관한 선행연구 및 권장사항이나 합의서에서 빠지지 않고 나오는 말이다. 이는 실제로 교육과 정 목표 달성의 성패를 좌우하므로 커뮤니케이션 교육을 하 고자 한다면 반드시 기억해야 한다. 필자의 대학에서는 2 개 학년에 걸쳐 커뮤니케이션 교육과정을 운영해오고 있는데, 한정된 자원을 나누어 할애하다보니, 일개 학년에 대해서는 경험학습을 제공할 수 없었고, 다른 학년의 학생들의 수업에 서는 경험학습을 제공할 수 있었다. 경험학습의 제공 여부에 따라 학생들의 동기, 수업태도, 만족도는 매우 달랐고 학습 성 과 역시 달랐다. 경험학습의 기회가 늘어날수록 학생들의 수 업만족도와 교육목표 달성도는 훨씬 높았다.

1) 표준화 환자를 이용한 면담 실습

경험학습이라 함은, 실제 환자와 면담기회를 주던, 모의환

Korean J Med Educ 2012 Mar; 24(1): 65-68.

http://dx.doi.org/10.3946/kjme.2012.24.1.65

pISSN: 2005-727X eISSN: 2005-7288

(C) The Korean Society of Medical Education. All rights reserved.

This is an open-access article distributed under the terms of the Creative Commons Attribution Non-Commercial License (http://creativecommons. org/licenses/by-nc/3.0/), which permits unrestricted non-commercial use, distribution, and reproduction in any medium, provided the original work is properly cited. 
Young-Mee Lee: Challenges in Communication Skills Education in Medicine: Based on Personal Experience and Reflection

자와 대화할 수 있는 기회를 주던, 학생들이 실제로 업무를 수 행하게 될 상황과 유사한 교육환경을 제공하고, 학생들이 실 제로 말하고 표현하고 느끼고 행동하게 하는 것을 말한다. 임 상실습 전 의과대학 교육에서 가장 효과적인 커뮤니케이션 교수방법으로 제안되는 것이 역할극과 비디오 촬영을 이용한 경험학습이다[2]. 필자의 대학에서도 의학과 2학년 학생들을 대상으로 표준화 환자를 이용하여 면담을 시행하는데 주제에 따라 혹은 가용 가능한 자원에 따라 일대일 면담과 그룹면담 을 복합적으로 사용하지만, 가능한 일대일 면담의 기회를 제 공하는 것이 효과적이다.

\section{2) 피드백}

표준화 환자와 면담 실습만으로 학생들의 행동변화를 유도 하는 데 한계가 있다. 면담 후에는 피드백과 자기성찰이 반드 시 뒤따라야 한다. 피드백은 교수와 표준화 환자 모두에 의해 제공될 때 가장 효과적이다. 현실적으로 튜터 교수의 확보에 어려움이 있기 때문에, 매 면담 시마다 교수의 피드백을 제공 하는 것은 현실적으로 불가능하다고 하더라도, 수업 초기에 새로운 행동요소를 가르칠 때 혹은 반드시 임상경험이 풍부 한 의사들의 조언이 필요한 주제의 경우(예로, 감정이 격앙되 어 있는 환자에 대처하는 법, 나쁜 소식을 전달해야 하는 사례 의 경우), 교수의 피드백만큼 학생들의 피부에 와 닿는 가르 침은 없다. 표준화 환자의 피드백은 환자의 목소리를 학생들 이 편안한 분위기에서 직접적으로 들을 수 있는 귀중한 시간 이다.

\section{3) 자기 성찰}

교수와 환자의 피드백은 행동 수정을 위한 유용한 피드백 이지만, 자기 성찰은 태도와 인식의 전환을 통한 자기 변화에 있어 가장 강력한 도구이다. 표준화 환자와 면담을 비디오 촬 영하는 것은 바로 자기 성찰을 위한 것이다. 그러나 어떤 형식 도 없이 학생들에게 자기 성찰을 요구할 경우, 이는 시간 낭비 가 될 수 있다. 필자의 대학에서는 커뮤니케이션 행동 요소로 구성한 채점표를 제공하고 녹화한 비디오 영상을 보면서 스 스로 자신의 행동을 점검하게 하거나, 자유기술형식의 자기 성찰일지(reflective journal)를 작성하게 하여 제출하게 한 다. 이러한 활동은 개별 혹은 그룹 활동으로 수행되며, 책임교 수의 디브리핑을 시간을 이용하여 학생들에게 피드백 된다. 자기 성찰과 평가는 학생들에게 때로는 귀찮은 과제로 여겨
질 수 있다. 그러나 자신의 모습을 거울에 비추어 보지 않고는 내 얼굴에 검댕이가 묻어 있는지 알 수조차 없는 것이다. 더구 나 성인들은 타인의 피드백보다는 자기 평가와 반성을 통하 여 배움의 필요성을 자각할 때 더 많이 배울 수 있다. 학생들 에게 귀찮은 과제를 수행하게 하는 목적과 이유를 분명히 설 명하고 설득한다면 충분히 이해할 것이다.

개인의 인식 변화를 통한 행동의 변화는 '실습-피드백-자기 성찰'이라는 일련의 학습과정을 통해서 이루어질 수 있다[3].

\section{2. 대학은 '경험학습'을 지원할 의지를 가지고 있어 야 하고 필요한 자원을 제공해야 한다}

\section{1) 대학의 새로운 학습 방법에 대한 의지와 행-재정 적 지원이 필요하다}

학습자의 인식과 행동의 변화를 유도하기 위해서는 경험학 습이 필요하다고 하였다. 그러나 경험학습 노동집약적이고 고비용의 투자를 필요로 하는 학습방법이다. 표준화 환자와 면담 수업을 위한 사례개발, 사례훈련, 표준화 환자 관련 비 용, 소그룹 활동을 위한 공간, 비디오 녹화 및 관련 기자재 등 많은 비용이 투입되어야 한다. 이러한 비용을 감당하겠다는 대학의 의지 없이는 원활한 운영이 불가능하다. 국내의 많은 대학들이 최근 교육관련 시설 설비에 대한 투자는 많이 증가 한 것이 사실이지만, 사례개발과 훈련, 교육자료 개발 등 교수 들의 지적 노력과 시간이 할애되어야 하는 부분에 대해서는 보상과 투자가 미흡한 것 같다. 표준화 환자 훈련 및 인건비에 투입되는 예산조차도 교육과정을 제대로 실행하기에는 턱 없 이 부족한 경우도 많다. 과거에 강의 위주의 교육에서는 수업 을 위하여 특별히 추가 비용이 발생하지 않았겠지만, 경험학 습을 제대로 운영하기 위해서는 대학의 행 - 재정적 지원이 반드시 추가되어야 함을 대학이 인식하고 지원해야 한다.

2) 수업 참여 교수의 모집과 확보는 대학의 공식적인 시스템을 이용해야 한다

재정적 지원보다 더 확보하기 어려운 부분은 '교수의 참여 와 교수개발이다. 필자의 경우, 6 년 동안 커뮤니케이션 교육 과정을 운영하면서, 소그룹 학습 운영을 위한 튜터 교수 확보 시, 자발적으로 수업 참여에 동의한 교수들의 도움을 받아 수 업을 운영해왔다. 초기에는 성공적인 것 같았다. 자발적으로 동참하였던 교수들은 교수개발 과정이 없더라도, 이미 본인 
의 커뮤니케이션에 대한 인식과 태도가 바뀌어 있고 교수목 표에 대한 인지도가 높기 때문에 수업 운영이 원활하였고 소 그룹 활동 시 교수자 간 피드백의 간극도 크지 않았다. 그러나 보상과 인정이 뒤따라주지 않는 자발적인 참여에만 의존할 경우, 충분한 인원의 튜터 교수를 지속적으로 확보하는 것이 불가하다는 것을 경험하였다.

경험학습과 튜터 교수를 활용할 계획을 가지고 있다면, 개 인적인 친분이나 자발적 참여를 원하는 동료 교수에 의존해 서는 안 된다. 장기적으로 수업을 운영하고 발전시켜 나가는 데 있어 장애요인이 될 수 있다. 수업 참여 및 튜터 교수의 모 집과 확보는 대학의 공식적인 요청과 절차에 따라 이루어져 야 하고 교수개발의 과정을 거쳐 수업에 참여하도록 하는 것 이 바람직하다. 환자 진료 경험이 많은 의사라고 해서 커뮤니 케이션 능력이 탁월하고 교육목표에 합당한 커뮤니케이션 교 육을 즉각적으로 학생에게 제공할 수 있는 것은 아니다. 효과 적인 커뮤니케이션 수업을 위해서는 참여교수를 위한 교수개 발이 필수적이다.

\section{3) '교수개발' 과정이 적절히 제공되고 있는가?}

학생들에게 커뮤니케이션 기술을 가르치기 위해서는 교수 가 먼저 핵심 커뮤니케이션 기술, 그 기술이 필요한 이유, 이 론적 배경 등에 대한 이해와 더불어 소그룹 활동을 촉진시키 는 기술, 피드백 기술 등을 숙지하고 있어야 한다. 의과대학 교수 중에 커뮤니케이션에 대한 전문적인 공부를 하였거나 경험이 있는 사람 혹은 자신이 의과대학 재학 시 체계적으로 커뮤니케이션이나 대인관계술을 배우고 익혔던 경우는 극히 드물다. 튜터 교수의 주관적인 경험도 중요하지만 효과적이 고 일관성 있는 교육을 제공하기 위하여 튜터 교수들의 표준 화와 일관성 유지가 반드시 필요하다. 또한 교수개발에 참여 하고 수업에 기꺼이 동참해주는 교수들이 자부심을 가지고 수업에 임할 수 있도록 대학의 아낌없는 지원과 보상 및 인정 이 필요하다.

\section{3. 학습자의 수준과 요구사항에 맞추어 수업내용과 방법을 편성해야 한다.}

커뮤니케이션 교육을 받을 대상 학생이 의예과 학생인지, 임상실습 전 학생인지, 임상실습과정 중인지, 전공의인지에 따라 대인관계술이나 커뮤니케이션 기술에 대한 인식과 필요
성의 정도는 매우 다르다. 의예과 학생들의 경우, 진료와 관계 된 커뮤니케이션 능력에 대해서는 관심도가 낮은 것은 당연 하겠지만, 일상에서의 커뮤니케이션 기술에 대한 관심도 역 시 높지 않은 것을 경험할 수 있었다. 즉, 필자의 대학에서는 의학과 진입 전 의예과 학생들에게 일반적인 커뮤니케이션 기술을 교육할 경우, 대인관계 및 소통능력을 향상시키고 의 학과에서 학습하게 되는 환자와 커뮤니케이션 기술을 배우는 과정과의 연계성을 확보할 수 있을 것이라는 취지에서 의예 과 2학년 과정에서 커뮤니케이션 교육과정을 운영한 경험이 있다. 그러나 의예과 학생들의 대다수는 자신의 커뮤니케이 션 능력 수준을 향상시켜야겠다는 요구 자체가 높지 않았으 며 이러한 학생들에게 '타인에 대한 공감' 등을 강조하고 효과 적인 대인관계 및 커뮤니케이션 기술이 좋은 의사의 기본적 자질임을 설득하는 것은 결코 쉽지 않았다.

반면 임상실습을 눈앞에 둔 의학과 학생들의 경우, 커뮤니 케이션 수업에 대한 인식 및 요구도가 높았다. 또한 이론 강의 에 지쳐있었던 학생들에게 역할극, 표준화 환자 면담, 교수하 고 토론하면서 환자에 의해 제공되는 피드백 등의 경험학습 은 신선한 자극이 되었다. 자신의 행동 변화를 모니터링하면 서 수업의 몰입도도 높았다.

교육의 대상이 되는 학습자의 상태와 요구를 정확히 분석 하는 것은 교육과정 편성과 계획 시 기본 중에도 기본이다. 그 러나 때론 가장 기초적인 것을 간과하는 경우가 있다. 기본은 지키지 않으면, 가장 큰 장애요인이 된다. 장애물을 처음부터 제거하지 않고 뛰는 경주는 완주할 수도 이길 수도 없다.

\section{4. 학교 수업과 진료현장에서의 일관성 있는 메시 지를 전달하는 것이 필요하다}

필자는 환자를 보지 않는 기초교수로서 '의료 커뮤니케이션' 수업을 운영하면서, 이런 질문을 받는다. "선생님이 지금 가르 치시는 것이 임상현장에서 실제 가능한 것인가요?" 행동 요소 하나하나를 따지자면 가능한 것도 있고 가능하지 못한 것도 있을 것이다. 가령 '환자에게 공감하라고 가르치고, '공감'을 표현하는 방법에 대한 행동 요소를 구체적으로 제시하지만, 바쁜 진료현장에서 그 행동 하나하나를 전부 실행할 수도 없 을 것이며 의사마다 그것을 구현하는 방식 역시 다를 것이다. 그러나 환자를 최우선으로 하는 마인드를 가지고 환자와 공 
감하려고 노력하는 마음은 결코 이론과 실제가 다를 수 없다. 병력 청취를 할 때, 열린 질문을 하고 환자의 말을 경청해주고 인정해주라고 가르친다. 그러나 실제 현장에서는 환자와 면 담이 폐쇄형 질문으로 이루어지고 환자가 말할 기회는 거의 주어지지 않는다. 학생들은 'mixed message'에 혼돈스러워 한다.

학교에서 이루어지는 수업은 임상현장에서 학생들이 환자 를 볼 때 행동으로 구현되는 것을 최종목표로 기획되고 운영 된다. 따라서 수업에서 가르치고 배운 것들은 임상현장에서 일관성 있는 메시지 로 반복·심화되어야만 예비 의사들의 가 치와 행동에 녹아들어갈 수 있다. 교수개발이 필요한 이유가 여기에 또한 존재한다. 더 많은 임상 의사들이 커뮤니케이션 기술과 수업에 관심을 가지고 진료현장에서 모범을 보여 줄 수 있도록 교수개발이 활발히 이루어져야 할 것이다.

\section{REFERENCES}

1. Makoul G, Schofield T. Communication teaching and assessment in medical education: an international consensus statement. Netherlands Institute of Primary Health Care. Patient Educ Couns 1999; 37: 191-195.

2. Report III. Contemporary issues in medicine: communication in medicine [Internet]. Association of American Medical Colleges; 1999 [cited 2012 January 3]. Available from: http://members.aamc.org/eweb/DynamicPage.aspx.

3. Kurtz S, Silverman J, Draper J. Teaching and learning communication skills in medicine. Abingdon, UK: Radicliffe Medical Press; 1998. 